\title{
Erratum to: Dual antiplatelet therapy with or without oral anticoagulation in the postdischarge management of acute coronary syndrome patients with an indication for long term anticoagulation: a systematic review
}

\author{
Jeffrey B. Washam ${ }^{1}$ - Rowena J. Dolor ${ }^{2}$ - W. Schuyler Jones ${ }^{2}$ - Sharif A. Halim ${ }^{2}$.

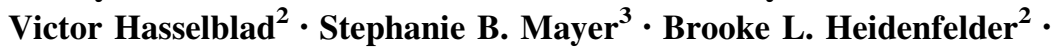 \\ Chiara Melloni
}

Published online: 20 May 2016

(C) Springer Science+Business Media New York 2016

\section{Erratum to: J Thromb Thrombolysis (2014) 38:285- 298 \\ DOI 10.1007/s11239-014-1094-1}

The below disclosure text was not submitted and hence not included in the original publication. The following disclosures need to be included:
1. "Research reported in this publication was supported by NIH T32 grant Endocrinology and Metabolism Research Training Program of the National Institutes of Health under award number NIH 5T32DK007012".

2. "The content is solely the responsibility of the authors and does not necessarily represent the official views of the National Institutes of Health."

The online version of the original article can be found under doi:10.1007/s11239-014-1094-1.

Jeffrey B. Washam

jeff.washam@duke.edu

1 Duke Heart Center, Duke University Medical Center, DUMC 3943, Durham, NC 27710, USA

2 Duke Clinical Research Institute, Duke University Medical Center, Durham, NC, USA

3 Division of Endocrinology and Metabolism, Department of Medicine, Virginia Commonwealth University, Richmond, VA, USA 